\title{
Percepção das emoções dos usuários do CAPS II: um relato de experiência
}

\author{
Jeciana das Virgens Botelho, ${ }^{I \star}$ Maristela Viana Lima ${ }^{I I}$ \\ ${ }^{I}$ Pontifícia Universidade Católica de São Paulo, São Paulo, SP, Brasil

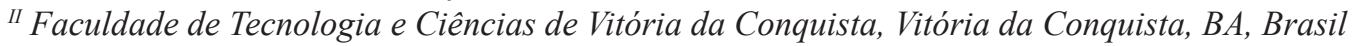

\begin{abstract}
Resumo
O presente artigo teve como objetivo relatar a experiência de uma estudante de Psicologia com os usuários do CAPS II de uma cidade da Bahia, descrevendo, a partir de um encontro com essas pessoas, as percepções e emoções vivenciadas em relação aos serviços prestados pela instituição, relacionando aos objetivos propostos pela instituição CAPS e o Movimento de Reforma Psiquiátrica. Os resultados obtidos na observação são de uma satisfação dessas pessoas com o serviço, demonstrando um cuidado a esses usuários que busca acolhê-los e permitindo uma reinserção social, oferecendo-lhes suporte para que possam atuar em sua comunidade com liberdade, dignidade, respeito e autonomia.
\end{abstract}

Palavras-chave: CAPS; Saúde Mental; Reforma Psiquiátrica; Centro de Atenção Psicossocial; Cuidado.

\section{Perception of the emotions from CAPS II users:}

\section{an experience report}

\begin{abstract}
The present article has like objective to report the experience of a Psychology student with the CAPS II on Bahia's State city, describing, from a moment with these people, the emotions and perceptions lived associated on the Institution's objectives, considering also to the objectives proposed by the CAPS institution and the Psychiatric Reform Movement. The results obtained by the observation is there's a satisfaction from these people according the service, representing an careful attitude for the users, trying to receive and permit a social reintegration, offering them support for express in your community, with freedom, dignity, respect and autonomy.
\end{abstract}

Keywords: CAPS; Mental Health; Psychiatric Reform; Care; Psychology.

\section{Introdução}

Breve histórico da loucura e da institucionalização psiquiátrica a partir do estudo de Michel Foucault

Vem de longa data colocar todo comportamento desviante à margem da sociedade. Inicialmente, os doentes mentais eram cuidados pelos seus parentes, enclausurados em suas casas ou atirados nas ruas à própria sorte. Surgiram então, os hospitais psiquiátricos, que mais pareciam prisões, sem estrutura física e de tratamento inadequado à demanda dessa população adoecida (PIMENTA, 2008).

Foucault - que dedicou parte de sua obra à compreensão da constituição do homem enquanto sujeito na história, e como o mesmo se relaciona com a questão da alteridade - fez uma análise do processo de percepção e vivência do fenômeno da loucura, que chama de "outro", sendo o louco, uma figura que esteve à margem dos discursos sociais, os "outros" epistemes, como eram chamados os loucos, os prisioneiros e os doentes, a partir da Idade Média, como comenta Haddock-Lobo (2008, p. 52):

A loucura existe nesta época [o Classicismo] como uma forma de sabedoria ou mesmo um caminho que conduz a ela (ou, como diz Foucault como a "força viva e secreta da razão", uma sabedoria que o louco possui em seu status de "figura cósmica", já que o seu delírio nada mais revela que a verdade do mundo - nesse sentido, a experiência renascentista da loucura tem, portanto, seu fundamento na realidade.

\footnotetext{
^Endereço para correspondência: Programa de Estudos Pós-Graduados em Psicologia Clínica da Pontifícia Universidade Católica de São Paulo. Campus Perdizes - Rua Ministro Godoi, 969 sala 4E-05. CEP: 05015-001 - São Paulo, SP, Brasil.E-mail: jeciana.botelho@hotmail.com, maristelapsi@hotmail.com
}

Foucault inicia sua crítica à visão social da loucura, a partir do fato de que, durante a Idade Clássica, os leprosos eram excluídos socialmente, e a loucura era vista como manifestação de sabedoria. Já na Idade Média, a mesma era conceituada como perda da razão e da moral, sendo o tratamento dado a loucos, semelhante ao prestado aos leprosos. (ALVES et. al. 2009).

Com a ruptura da associação da lepra aos confinamentos, no final da Idade Média, ocorre o surgimento da Nau dos Loucos, em que os loucos e prisioneiros eram colocados em naus, expulsos de suas cidades, vagando para lugares distantes, simbolizando uma maneira de encontrar a fortuna e as verdades de seus destinos (VIEIRA, 2006-2007). Foucault, entretanto, faz uma análise de que a Nau dos Loucos tinha por objetivo a busca por segurança nas cidades, caso o fenômeno seja visto no contexto do surgimento do mercantilismo, e do aquecimento do comércio nas cidades; afastando todos os "outros", que representavam ameaça, demonstrando uma inquietude social em relação à loucura, no final da Idade Média e no início da Renascença. (ALVES et. al., 2009).

Somente a partir da Revolução Francesa, com os ideais de "Igualdade, Liberdade e Fraternidade", começam a surgir os hospitais gerais como forma de acolhimento dos "excluídos" socialmente. Naquele momento, as ideias de saúde e doença pautavam-se na concepção social (ALVES et al., 2009). Porém, Foucault (1997) faz uma crítica a esse modelo, que veio a ser mais bem percebido, no final do século XVII, e, até mesmo, escandalizado, ao 
final do séc. XIX, com o início do processo de internamentos - não como um procedimento médico, mas uma forma de afastar os "outros" perigosos da sociedade. Nos hospitais eram internados os loucos, libertinos, prostitutas, insanos, criminosos, e os enfermos, sem haver nenhuma distinção sobre eles. Tais instituições eram utilizadas para desempenhar um papel mais jurídico, normalizador e, como Alves (et. al. 2009) denomina, uma "terceira ordem de repressão".

Além dessa preocupação, outra é evidente na história da loucura feita por Foucault, que se relaciona diretamente à segunda crítica que apontei no começo dessas reflexões: o internamento do século XVII não é um estabelecimento médico, mas uma estrutura sem jurídica que, além dos tribunais, decide, julga e executa. Na organização das casas de internamento, portanto, não está presente nenhuma ideia ou liderança médica. (VIEIRA, 2006-2007, p. 7).

A partir da escandalização do internamento, da revolução médica, no século XX e da evolução da farmacologia, diversas reflexões sobre a loucura, enquanto doença, foram surgindo, fornecendo à atribuição médica um lugar privilegiado nos estudos da loucura e suas formas de tratamento e cura. O sujeito deixou de ser visto apenas como um corpo, mas com potencialidades, dando inicio a partir de Pinel, a evolução dos tratamentos dados a essas pessoas (CAPONI, 2009). A partir dessa perspectiva da busca de uma cura, surge a "possibilidade de uma psiquiatria da observação, de um internamento de aspecto hospitalar e do diálogo do louco com o médico." (VIEIRA, 2006-2007, p.12).

Tais reflexões médicas e suas novas práticas dão surgimento a uma nova classificação das doenças: de aspecto físico, psicológico e moral; dando à loucura uma conotação moral e a visão de culpa a partir do sujeito enquanto responsável pela doença. Vieira (2006-2007) e Alves (2009) apontam para o fato de, mesmo sendo delegado ao louco o direito a um tratamento médico, foi tirada dele a cidadania, a visão de igualdade, excluindo a loucura, definitivamente, do espaço social. Nesse contexto, ocorre o aparecimento da Psicologia enquanto ciência desligada da Psiquiatra e, a ela, foi dado essa tratamento de culpabilização ao louco pelos seus atos. (VIEIRA, 2006-2007; ALVES, 2009).

Segundo Foucault (1978 p. 18), "O que se encontra no começo das coisas não é a identidade ainda preservada da origem - é a discórdia entre as coisas, é o disparate". Surge, então, uma noção social de medo em relação aos hospitais psiquiátricos. $\mathrm{O}$ aparecimento da psicologia, para Foucault, passa a refletir e constituir o ser humano em sua subjetividade.

O louco também é detentor da sua verdade, mas essa verdade está oculta e, como ele não consegue alcançá-la, nem decifrála, então ele clama desesperadamente para que ela seja, enfim, revelada. Quem atenderá a esse chamado? Está construído o campo que possibilita à psicologia tratar o louco e interná-lo em seus confinamentos. (VIEIRA, 2006-2007, p. 20).

Fractal, Rev. Psicol., v. 27 - n. 2, p. 160-164, 2015
Segundo Haddock-Lobo (2008), o objetivo de Foucault consistiu em compreender a loucura na visão Moderna, que passou a ser percebida como "doença mental". Surge a classificação médica do louco, o tratamento de sua "doença" e cura dentro dos hospitais psiquiátricos, rejeitados e temidos socialmente, a partir de métodos de internação e confinamento, tratamento punitivo, a princípio, e posteriormente com a farmacologia, sedativo, limitando o sujeito de suas potencialidades.

O sujeito louco, aquele vivia numa lógica outra a da sociedade, e que antes era visto por sua genialidade e criatividade, elevado à "descoberta do cogito" passou a ser compreendido pelo saber médico, como o doente e, junto a esse nome, o incapaz de si, defeituoso, necessitado de tratamento e cura e passível de enclausuramento. Junto a uma patologização da loucura, surge uma transformação na relação com o outro que, pelo adjetivo que lhe é atribuído, é dado ao médico o poder de curá-lo de sua grave enfermidade. Nesta lógica em que as ciências médicas se inserem, detém-se, então, o poder sobre o "sujeito louco" e limita-o ao horizonte de possibilidades do nome que lhe é dado: doente. E, num discurso de libertação (desse mal: a doença), rompe-se, pela imposição do discurso médico, a ideia de liberdade e o "louco" torna-se reduzido a uma norma, submisso ao "tratamento" de sua doença. O discurso médico, como um elogio à razão e ao método, impôs à loucura uma linguagem vazia que cessou qualquer possibilidade de diálogo com esse "outro".

Em sua obra, Foucault (1977) denunciou o surgimento de uma lógica social de poder e controle sobre o outro, marcada por uma extrema patologização de modos outros de existir, trazendo ao nome "louco" uma marca de tudo o que está fora das normatizações sociais, subordinado à verdade médica num discurso de inibição e exclusão, com uma postura "tratamento e cura" da existência outra.

A desinstitucionalização do "louco" e o surgimento de novos paradigmas de sujeito e de tratamento dos transtornos

Uma nova visão sobre a loucura surge como uma desconstrução dos paradigmas tradicionais, a partir do fracasso da psiquiatria em sua tentativa de "curar a loucura" e sobre a crítica das ciências naturalistas com concepções que subjetivam o processo de doença e loucura. (TORRE; AMARANTE, 2001). Basaglia (1985 apud TORRE; AMARANTE, 2001) coloca a incapacidade da psiquiatria relacionada a uma nova construção do real e da produção de subjetividade, que recoloca em debate a própria ciência e a psiquiatria.

A partir daí, segundo Torre e Amarante (2001), o "louco" começou a ser considerado em sua subjetividade e cidadania, e os processos de tratamento da loucura começaram a se basear na socialização e na busca pela autenticidade do sujeito - valorizando o cuidado pela família e dando início ao processo de desisnstitucionalização do louco.

Após a década de 1990, novos paradigmas surgem com relação aos doentes mentais, tratando-se do movimento de luta antimanicomial, da desinstitucionalização, do retorno ao lar - um novo olhar da família, da so- 
ciedade e dos profissionais da área. A reforma psiquiátrica no Brasil sustentou o redirecionamento do modelo assistencial para serviços de bases comunitárias, criando serviços substitutivos que possibilitaram a desospitalização. Dentre os avanços alcançados por esse movimento, destaca-se: ações de saúde mental em UBS (Unidades Básicas de Saúde), unidades ambulatoriais de atenção intensiva em saúde mental (hospitais-dia, CAPS - Centros de Atenção Psicossocial); centros de convivência; unidade de saúde mental em hospital geral (emergência e enfermaria), isoladamente ou integrados em sistemas de referência e contrarreferência (BARROSO et al., 2004) e o Programa De Volta Para Casa - que visa garantir a portadores de transtornos mentais com longo tempo de internação, reintegração social, assistência e acompanhamento fora do ambiente hospitalar (BRASIL, 2002).

O Centro de Atenção Psicossocial - CAPS é uma instituição municipal criada com o valor estratégico de substituir os hospitais psiquiátricos para a Reforma Psiquiátrica Brasileira. É sua função oferecer acolhimento e acompanhamento clínico em regime de atenção diária a pessoas com transtornos mentais persistentes, procurando promover a reinserção social das mesmas pelo acesso ao trabalho, lazer, exercício de direitos civis e fortalecimento de laços sociais (BRASIL, 2002).

Existem diferentes tipos de CAPS, implantados de acordo as necessidades e características de cada município. São do tipo I, II, III, Álcool e Drogas (CAPS AD) e Infanto-juvenil (CAPS IA).

Os parâmetros populacionais para a implantação destes serviços são definidos da seguinte forma (BRASIL, 2002, online):

- Municípios até $\mathbf{2 0}$ mil habitantes - rede básica com ações de saúde mental

- Municípios entre 20 a $\mathbf{7 0}$ mil habitantes CAPS I e rede básica com ações de saúde mental

- Municípios com mais de 70 a 200 mil habitantes - CAPS II, CAPS AD e rede básica com ações de saúde mental

- Municípios com mais de 200 mil habitantes - CAPS II, CAPS III, CAPS AD, CAPS IA, e rede básica com ações de saúde mental e capacitação do SAMU.

Os CAPS fazem parte de um processo de desinstitucionalização que pressupõe criação de possibilidades reais de subjetividade e sociabilidade, que supera a divisão entre a utilização medicamentosa e a psicoterapia. Para alcançar as metas propostas, é preciso que essa instituição siga um modelo de atendimento interdisciplinar. Sendo assim, a qualidade do serviço prestado depende, entre outros fatores, da influência mútua entre os diversos profissionais da equipe e das relações deles com os usuários e a sociedade, evitando a representação de um modelo manicomial caracterizado pelo predomínio do distanciamento e pelas relações hierárquicas. (BRASIL, 2012b).

\section{Objetivos e caminho de pesquisa}

O município pesquisado conta com as instalações de um CAPS II, CAPS IA e um CAPS AD, implantados pelo Governo Municipal, que funciona de forma integrada à rede municipal de saúde, com o objetivo de cuidar das pessoas em sofrimento psíquico. Nesses anos de existência, além de reabilitar a saúde dos usuários, o CAPS II tem atuado no resgate da cidadania dos usuários e promover a reinserção social destes. Pensando nos objetivos propostos de integração social e valorização do sujeito com sofrimento psíquico como uma forma eficaz e digna de tratamento e promoção da saúde mental, o objetivo desse trabalho é relatar a experiência de uma estudante de psicologia com os usuários do CAPS II da cidade de Vitória da Conquista, na Bahia, descrevendo, a partir de um encontro com esses usuários, as percepções e emoções vivenciadas com relação aos serviços prestados pela instituição.

O relato ocorreu a partir da observação numa vivência com os usuários do CAPS II, em evento organizado pela instituição na Associação Atlética Banco do Brasil - AABB / Vitória da Conquista. Por ser uma observação livre, a perspectiva de análise se deu a partir do olhar para o comportamento dos presentes, levando em conta as emoções demonstradas, o nível de interação social e a participação ativa dos usuários no evento, a partir da relação entre os objetivos das políticas de reforma psiquiátrica e as percepções da observadora.

\section{Relato e análise de experiência}

A experiência ocorreu durante um evento de confraternização entre os usuários, familiares, profissionais do CAPS II e pessoas do convívio social, tematizado pelas festas juninas tradicionais na Bahia. A observação foi feita de modo natural, anônima, sem interferência no ambiente. A análise foi realizada partindo das experiências vividas por uma estudante de Psicologia no momento da confraternização, guiadas pelos seguintes fatores: Emoção, Sociabilidade, Apoio e Valorização Social.

\section{Emoção}

Foi possível perceber que as pessoas demonstravam uma grande satisfação durante a confraternização; não somente os usuários e profissionais do CAPS II como, também, os demais presentes. Foi perceptível um semblante de alegria e animação que os usuários exibiam no evento, e como se comportavam com desenvoltura e espontaneidade, levando-me a sugerir que eles se sentiam à vontade uns com os outros.

\section{Sociabilidade}

Independente do sofrimento psíquico vivido por cada pessoa, pude perceber com clareza que havia uma grande interação entre os usuários do serviço e entre as outras pessoas presentes no evento, que se comunicavam entre si e com desconhecidos por conversas, danças, brincadeiras. Essa observação abre à compreensão da possibilidade de um modo de atendimento que, ao visar a integração e o desenvolvimento social dos usuários, cria nessa instituição uma pequena comunidade onde o acesso e a so- 
cialização entre todos as pessoas presentes não somente parece ser livre, como estimulado também, desenvolvendo um clima de amizade e apoio mútuo.

Apoio e valorização social

O tratamento dispensado aos usuários no momento da observação refletia um clima de acolhimento, de equidade pelas expressões de satisfação e alegria vistas neles e nos gestos em que se percebe uma abertura ao contato com o outro. Nesse quesito, partindo da maneira como as pessoas presentes interagiam, é possível perceber que houve, no tratamento dispensado aos usuários, um modo de cuidado fundado no apoio e valorização social aos que vivenciam algum tipo de sofrimento psíquico e procuram o serviço.

\section{Conclusão}

A percepção geral, enquanto estudante de psicologia, em torno da satisfação dos usuários do CAPS II nesse momento de confraternização, leva a concluir que existe um movimento dentro da instituição para a integração social, o desenvolvimento de laços fortalecidos e a preocupação dos profissionais em proporcionar uma abertura para esses usuários que os permita desenvolver sua autonomia e agir ativamente em sua comunidade. Prática que está de acordo aos objetivos principais da instituição: de oferecer não somente acompanhamento clínico, mas promover a reinserção social pelo acesso ao trabalho, lazer e o fortalecimento dos laços sociais. Os resultados colhidos pelo trabalho dessas instituições mostram a importância de se ter um olhar diferenciado à saúde mental, oferecendo aos usuários um tratamento que supere apenas o acompanhamento clínico: acolhimento e valorização social, além de permitir e garantir meios ao indivíduo de desenvolver suas potencialidades e atuar com liberdade e dignidade, como agente ativo na sociedade.

Outro fator importante a se destacar é a criação de um ambiente de equidade entre os profissionais, usuários e familiares, importantíssimo para o desenvolvimento de um trabalho que vise a reintegração social dos acolhidos. O conceito de equidade aparece como princípio complementar ao da igualdade, e fala do tratamento às diferenças em busca da igualdade de acesso e tratamento entre os indivíduos.

É bastante observável uma melhora na qualidade de vida dos usuários desses serviços de saúde. Em consonância com o pensamento de Torres (2001), os melhores espaços de cuidado são a cidade, a comunidade e a participação nesta. Utilizando a caracterização de doença por Sonenreich e Bassit (1979), chegamos ao ponto de que a doença existe quando se perde a liberdade de ser.

quando encontramos distúrbios psíquicos que podem ser relacionados com uma alteração das funções do sistema nervoso e, para uma pessoa, representam uma perda da liberdade de escolher seus pensamentos, afetos, suas ações, tentamos fazer um raciocínio médico e falamos de doença mental. (SONENREICH; BASSIT, 1979, p 3).
Da mesma forma, ousaria, também, dizer doentio o modo como o sujeito é tratado, se este modo impede a sua liberdade de expressão e autonomia e, por isso, é de grande importância haver um olhar diferenciado para o homem, em sua individualidade e suas possibilidades de ser.

Essa forma de olhar o homem e seus modos específicos de viver, sejam ou não patológicos, deve existir não somente em instituições que focam o desenvolvimento social, como os Centros de Atenção Psicossocial, mas se estender primeiramente para a formação dos profissionais que neles atuam. É essencial que nas graduações da Saúde, em específico nos cursos de Psicologia, haja desde o início a desconstrução de preconceitos e engessamentos presentes na sociedade, que segregam e colocam à margem os indivíduos que vão de encontro aos padrões sociais, que nivelam os indivíduos em nome de uma ideia de "boa saúde" predeterminada, muitas vezes, por questões político-sociais, para uma visão de mundo - e cuidado do outro, pautados nos princípios de equidade e humanização da saúde. Humanizar o tratamento à saúde aponta para uma transformação cultural da gestão e das práticas desenvolvidas pelos profissionais em seus diversos âmbitos de trabalho, adotando uma postura de acolhimento do desconhecido, uma conduta ética de respeito ao outro, entendido como um sujeito em sua individualidade e complexidade de existência, e um cidadão em sua integralidade e não apenas como um consumidor de serviços de saúde.

Tal experiência se mostrou em seu todo como positiva e comprovou um exemplo de modo de se acolher e cuidar de uma pessoa em sofrimento. Essa é uma visão que deve ser adotada pelos profissionais de saúde mental: passar a olhar o "outro" como o "mesmo", e, como Foucault nos provoca a refletir, estar sempre em atitude de resistência aos poderes subjetivadores e estranhamento aos comportamentos regrados que nos nivelam, deixando a visão única da "cura e tratamento" das doenças "do corpo" para a atenção à subjetividade do indivíduo, buscando a construção de um modo de cuidar que abra ao sujeito as possibilidades de existir em sua autonomia e reinventar-se em sua singularidade.

\section{Referências}

ALVES, C. F. O. et al. Uma breve história da reforma psiquiátrica. Neurobiologia, [S.1.], v. 72, n. 1, p. 85-96, jan./ mar. 2009.

BARROSO, A. G. C. et al. Transtornos mentais: o significado para os familiares. RBPS, [S.1.], v. 17, n. 3, p. 99-108, 2004. Disponível em: < http://ojs.unifor.br/index.php/RBPS/article/ view/686/2054 > Acesso em: 3 maio 2015 .

BRASIL. Ministério da Saúde. Portaria GM n 336, de 19 de fevereiro de 2002. Define e estabelece diretrizes para o funcionamento dos Centros de Atenção Psicossocial. Diário Oficial da União 2002. Disponível em: <http://bvsms.saude, gov.br/bvs/saudelegis/gm/2002/prt0336_19_02_2002.html>. Acesso em: 18 maio 2015.

CAPONI, S. Michael Foucault e a persistência do poder psiquiátrico. Ciência \& Saúde Coletiva, v. 14, n. 1, p. 95-103, 2009. Disponível em: <http://www.scielosp.org/pdf/csc/v14n1/ a15v14n1.pdf $>$ Acesso em: 18 maio 2015. 
FOUCAULT, M. O nascimento da clínica. 6. ed. Rio de Janeiro: Forense Universitária, 1977.

FOUCAULT, M. Nietzsche, a Genealogia e a História. In: Microfisica do Poder. Rio de Janeiro; Graal, 1978. p. 15-37.

FOUCAULT, M. A História da Loucura na Idade Clássica. São Paulo, Perspectiva, 1997.

HADDOCK-LOBO, R. História da Loucura de Michel Foucault como uma História do outro. Veritas, Porto Alegre, v. 53, n. 2, p. 51-72, 2008. Disponível em: http://revistaseletronicas.pucrs. br/ojs/index.php/veritas/article/view/4458. Acesso em: 18 maio 2015.

PIMENTA, E. S. A relação com as famílias no tratamento dos portadores de transtorno mental realizado no Centro de Atenção Psicossocial. 2008. Dissertação (Mestrado em Psicologia)-Pontifícia Universidade Católica de Minas Gerais, Belo Horizonte, 2008. Disponível em: $<$ http://www1.pucminas. br/documentos/dissertacoes_eliane_souza.pdf $>$ Acesso em: 18 maio 2015.

PINEL, F. Tratado médico-filosófico sobre a alienação mental. Porto Alegre: UFRGS, 2007.

TORRE, E. H. G.; AMARANTE, P. Protagonismo e subjetividade: a construção coletiva no campo da saúde mental. Ciência \& Saúde Coletiva, Rio de Janeiro, v. 6, n. 1, p. 73-85, 2001. Disponível em: <http://www.scielo.br/scielo. php? script=sci_arttext\&pid=S1413-81232001000100006\&lng =en\&nrm=iso $>$. Acesso em: 18 maio 2015.

SONENREICH, C.; BASSIT, W. O conceito de psicopatologia: distúrbio psíquico, doença, anormalidade. São Paulo: Manole, 1979.

VIEIRA, P. P. (Org.). Reflexões sobre A História da Loucura de Michel Foucault. Revista Aulas - Dossiê Foucault, n. 3, dez. 2006 - mar. 2007. Disponível em: < http://www.ifch.unicamp. br/ojs/index.php/aulas/article/view/1934 >. Acesso em: 18 maio 2015.

Recebido em: 14 de julho de 2012 Aceito em: 25 de março de 2015 